\title{
AS MUDANÇAS NA GESTÃO E ORGANIZAÇÃO DA ESCOLA: A PARTICIPAÇÃO COMO ESTRATÉGIA DE REFORMA
}

\author{
CHANGES IN THE MANAGEMENT AND ORGANIZATION \\ IN THE SCHOOL: THE PARTICIPATION AS \\ A STRATEGY FOR REFORM \\ LES CHANGEMENTS DANS L'ADMINISTRATION ET \\ L'ORGANISATION DE L'ÉCOLE : LA PARTICIPATION \\ COMME STRATÉGIE POUR LA RÉFORME \\ LOS CAMBIOS EN LA GESTIÓN Y ORGANIZACIÓN \\ DE LA ESCUELA: LA PARTICIPACIÓN \\ COMO ESTRATEGIA DE REFORMA
}

Luís Gustavo Alexandre da Silva*

\section{RESUMO}

$O$ artigo pretende evidenciar aspectos significativos do processo de implementação na escola pública de um modelo racional econômico de gestão, consubstanciado no Plano de Desenvolvimento da Escola (PDE), e analisar os desdobramentos ou conseqüências desse movimento no âmbito da produção do trabalho escolar e nas formas de participação, relacionando sua lógica ao movimento ampliado de transformação das relações de acumulação capitalista. $O$ estudo evidenciou que a metodologia de trabalho instituida pelo PDE materializa um modelo de organização e de gestão da escola que limita a participação dos agentes escolares à execução de procedimentos gerenciais, destituindo o conceito de uma perspectiva mais política e universal, visando o redimensionamento do poder na sociedade.

Palavras-chave: Gestão escolar. Racionalidade econômica. Participação-execução.

\footnotetext{
* Doutorando e Mestre em Educação pela Universidade Federal de Goiás (luisgas@bol.com.br).
} 


\section{INTRODUÇÃO}

Este artigo analisa questôes referentes ao tema da gestão e da organização da escola, visando apreender o movimento, as contradiçôes e o processo de hegemonia inerentes à implementação na escola pública de um modelo econômico e produtivista de organização, de gestão e de controle da produção do trabalho escolar. ${ }^{1}$

Para delimitarmos com precisão o problema a ser abordado no artigo, fez-se necessário focalizar as características e os princípios norteadores do modelo de gestão consubstanciado no Plano de Desenvolvimento da Escola - PDE, objeto central da investigação. O PDE torna-se fundamental para a pesquisa porque constitui uma referência de organização e de gestão para a escola pública fundamentada nos princípios de eficiência e de eficácia no trabalho docente. Nesse sentido, pesquisar a organização, a gestão escolar e as formas de participação implica compreender a concepção de educação e a lógica que fundamenta esse plano e, sobretudo, seus desdobramentos na dinâmica escolar.

O PDE, de acordo com seus formuladores, é um dos produtos ${ }^{2}$ do Fundo de Fortalecimento da Escola (Fundescola), ${ }^{3}$ que surgiu em 1998, destinado às regióes Norte, Nordeste e Centro-Oeste, para superar os graves problemas de acesso e de permanência dos alunos, com qualidade, no ensino fundamental, situação que atingia uma grande parte da sociedade, e cuja possibilidade de superação perdia-se na ineficaz organização burocrática escolar (AMARAL SOBRINHO, 2001).

Segundo Amaral Sobrinho e Xavier (1999), para ordenar essas aspirações, o PDE busca o direcionamento da ação escolar para obtenção de melhores resultados, acomodando o modelo administrativo gerencial na solução dos problemas da escola. Esses autores definem os objetivos do plano:

o PDE é um processo gerencial de planejamento estratégico que a escola desenvolve para a melhoria da qualidade do ensino, elaborado de modo participativo com a comunidade escolar (equipe escolar e pais de alunos). O PDE define o que é a escola, o que ela pretende fazer, aonde ela pretende chegar, de que maneira e com quais recursos. É um processo coordenado pela liderança da escola para o alcance de uma situação desejada, de uma maneira eficiente e eficaz, com a melhor concentração de esforços e recursos. (AMARAL SOBRINHO; XAVIER, 1999, p. 19)

A transferência dessa lógica gerencial para o cotidiano escolar, por meio da elaboração do planejamento estratégico, da clareza dos objetivos, da rotina administrativa definida, da internalização da missão da escola e do gerenciamento científico dos processos a serem realizados na escola pública está atrelada a recursos financeiros. ${ }^{4}$

Segundo as orientaçôes dos organismos multilaterais apresentadas nas conferências internacionais de educação realizadas a partir da década de $1990,{ }^{5}$ os problemas de qualidade na educação estavam relacionados, em grande parte, ao modelo de gestão aplicado nas escolas. De acordo com essa argumentação, o modelo centralizado de gestão e de organização da escola utilizado durante anos nos países em desenvolvimento era burocrático e ineficaz para alcançar os objetivos prioritários para o desenvolvimento educativo do país. Em decorrência da ausência de controle e de parceria com os pais e a comunidade, 
bem como a incompetência administrativa dos diretores, o sistema educacional e as unidades escolares apresentam grande inoperância para atender às necessidades emergentes da sociedade (AMARAL SOBRINHO, 2001).

A análise de Amaral Sobrinho (2001) relaciona os problemas de qualidade na educação à ineficiência do modelo de organização e gestão burocrática utilizada nas escolas, e, para superar esse quadro, considera necessárias soluções de caráter gerencial vinculadas à administração empresarial capitalista. Entretanto, pode-se indagar: qual a concepção de qualidade que o plano defende em suas estratégias de organização e gestão da escola? Será que os problemas de qualidade da educação se resumem à ineficiência da organização burocrática escolar?

Paro (2001) contrapõe-se a essa lógica, pois compreende a gestão como mediação para o alcance de determinados fins "socialmente relevantes e humanamente defensáveis a dirigir a ação escolar" (p. 96). Para esse autor, a produtividade da escola deve ser medida tendo em vista referenciais mais abrangentes, como a "proporção de seus alunos que ela consegue levar a se apropriar do saber produzido historicamente" (p. 94-96). Na essência dessa concepção de educação, compreende-se a gestão como uma mediação para a transformação democrática da sociedade.

Entretanto, nesse campo, estabelece-se uma disputa teórica acerca das finalidades da educação, que, conseqüentemente, se desdobra no conceito de qualidade, nas estratégias de gestão escolar e nos objetivos a serem alcançados. A pesquisa realizada insere-se no contexto de disputa entre concepçôes distintas de educação e de sociedade que se materializam, por meio de políticas públicas para a educação, como demonstra a implementação do PDE nas regiōes Norte, Nordeste e Centro-Oeste.

Assim, a pesquisa pretende desvelar a concepção de gestão e de organização em algumas escolas públicas goianienses, que, ao manterem contato com o PDE, revelaram uma nova dinâmica que precisa ser compreendida e analisada. Para apreender as transformações ocorridas na escola, fundamentou-se a pesquisa no recolhimento de dados empíricos, por meio de entrevistas semi-estruturadas e de documentos oficiais do Fundescola, visando compreender a estrutura do plano, os seus objetivos, a metodologia e as etapas que fazem parte do processo até a liberação dos recursos para a escola.

O processo de pesquisa empírica pode ser dividido em duas fases. A primeira foi a realização de entrevistas nas escolas públicas goianienses em conjunto com os pesquisadores vinculados à Associação Nacional de Política e Administração da Educação (Anpae). ${ }^{6}$ Nessa pesquisa foram coletados discursos proferidos pelos agentes escolares a respeito da temática: gestão e organização escolar após a inserção do PDE nas escolas estaduais e municipais no município de Goiânia. A pesquisa visava analisar as mudanças ocorridas na escola relacionadas ao PDE, tendo por base os seguintes temas: a concepção do PDE na visão dos agentes escolares; a forma de preparação para implantação do PDE; o planejamento e execução do plano; a avaliação dos cursos ministrados por meio do PDE; a avaliação do plano; as perspectivas do PDE; a relação entre PDE e Projeto Político Pedagógico (PPP); o papel do diretor na gestão do plano; o PDE e as novas tecnologias; a autonomia escolar com o PDE; a gestão democrática no PDE; a posição dos agentes em relação ao PDE; as instâncias de participação; a participação na execução do PDE; e a formação continuada dos professores com base no plano. 
A segunda fase de realização das entrevistas semi-estruturadas, específica deste trabalho, ocorreu de forma individual, pela necessidade de ampliar a compreensão das contradições e, mais especificamente, focalizar as formas de participação existentes na escola pública goianiense, após a implementação do PDE.

A convergência entre as duas pesquisas é que ambas analisam as transformaçôes ocorridas na escola, após a implementação do PDE, com o objetivo de compreender as transformaçōes ocorridas em relação à gestão e à organização escolar. Entretanto, os focos são distintos. A primeira pretendeu captar o conjunto das transformações em relação à gestão e à organização da escola, utilizando diversas categorias, ao passo que a segunda enfoca também a gestão e a organização da escola, porém prioriza as formas de participação, analisando as relações entre os procedimentos gerenciais do plano e o controle, as resistências e tensões existentes, a formação de uma cultura participativa, dentre outros; enfim, busca conhecer maiores detalhes do processo de transformação, por meio de uma categoria em especial. ${ }^{7}$

Nessa segunda fase foi escolhida uma das cinco escolas públicas goianienses envolvidas na pesquisa "Novos modelos de gestão da Educação Básica: o que mudou na escola?", para apreender com maior precisão a dinâmica, as contradições e os conflitos existentes na organização e na gestão da escola pública, e, mais especificamente, os desdobramentos na forma de organização do trabalho docente e da participação.

No artigo serão apresentados apenas os resultados da segunda fase da pesquisa, relativa ao estudo de caso de uma escola em Goiânia em que foram realizadas 10 entrevistas semi-estruturadas, com professores, coordenadores pedagógicos, coordenadores do PDE, diretor e funcionário, focalizando, especificamente, as novas formas de participação existentes no conjunto da escola.

A pesquisa pretende desvelar algumas questôes em relação aos efeitos da lógica gerencial contida no PDE sobre a gestão e a organização da escola e as formas de participação existentes, dentre elas a organização do PDE no tocante ao cumprimento das ações: Aumentou ou diminuiu o controle e a cobrança no espaço escolar? Que tipo de participação se instituiu na escola? Com a instituição do PDE houve uma maior participação do coletivo escolar na tomada de decisões? A concepção de gestão contida no PDE interfere na construção da democracia? Qual o impacto do PDE no modo de participação dos agentes escolares e na sua compreensão da gestão, da organização escolar e dos fins da escola? Em que moldes deve ser concebida a participação no âmbito da escola?

Nesse sentido, o estudo analisa a concepção de gestão e de organização da escola após a implementação do PDE, utilizando a categoria participação como mediadora do movimento inerente à dinâmica interna da escola. 


\section{A RACIONALIDADE ECONÔMICA NEOLIBERAL, O MODELO ADMINISTRATIVO GERENCIAL E A REFORMA EDUCATIVA BRASILEIRA NA DÉCADA DE 1990}

Em muitos países em desenvolvimento, a aplicação das políticas neoliberais de mercado foram intensas, em decorrência da necessidade de adaptar rapidamente essas nações às novas formas de acumulação, que, na prática, significavam formas atualizadas de exploração. ${ }^{8}$

O Brasil insere-se nesse cenário, uma vez que obedece aos princípios estabelecidos por esses organismos multilaterais. A reforma da estrutura econômica brasileira, ocorrida a partir do início da década de 1990, reproduz esse projeto do capital internacional, consubstanciado nos princípios do Consenso de Washington, que se materializou por meio das seguintes medidas: disciplina fiscal, redefinição das prioridades dos gastos públicos, reforma tributária, liberalização do setor financeiro, manutenção das taxas de câmbio competitivas, liberalização comercial, atração das aplicações de capital estrangeiro, privatização das empresas estatais, desregulamentação da economia e proteção de direitos autorais (GENTILI, 2001).

Esse modelo econômico neoliberal de mercado, consubstanciado no Consenso de Washington e reeditado como alternativa ao projeto keynesiano, foi o resultado de uma nova hegemonia liberal conservadora, que contou com a formulação teórica e adesão de alguns economistas e cientistas políticos que reconstituíram antigos princípios liberais. Dentre eles, pode-se destacar Hayek (1990), que defende a liberação dos indivíduos das interferências do Estado," que deve garantir-lhes apenas a previsão da ação estatal, de forma a possibilitar a utilização desses conhecimentos para a elaboração de seus próprios planos individuais. $\mathrm{O}$ indivíduo, a liberdade e a concorrência são os núcleos da teoria neoliberal de mercado, e o Estado deve limitar-se a estabelecer normas aplicáveis a situaçōes gerais, deixando os indivíduos livres em tudo, porque só os indivíduos conhecem plenamente as circunstâncias relativas a cada caso e a elas podem adaptar suas açôes. Para Friedman (1977), a interferência do Estado na dinâmica econômica e política da sociedade conduz a um excesso de conformidade pelos indivíduos; portanto, a principal função do Estado é eximir-se de qualquer tipo de atuação econômica, garantindo a livre concorrência e a liberdade para que os indivíduos possam conquistar seus objetivos.

Pode-se dizer que as formulações teóricas dos economistas centralizadas na ação do mercado e, em certa medida, dos cientistas políticos, herdeiros da escola de Chicago, ${ }^{10}$ ao desenvolverem a teoria da escolha racional ${ }^{11}$ ou elaborarem métodos baseados no individualismo econômico, para a compreensão do comportamento político e dos motivadores que interferem na ação social, constituíram ideologicamente as bases para a elaboração de um novo modo de regulamentação coerente com o regime de acumulação flexível, que tem como pressupostos o individualismo, a racionalidade econômica, a desorganização coletiva dos trabalhadores etc. A escola de Chicago é uma grande referência para a organização do capitalismo contemporâneo, uma vez que suas teorias econômicas e sociais contribuíram para a elaboração das bases constituintes de um novo modo de regulamentação.

Esses princípios teóricos materializaram-se em políticas públicas, principalmente na década de 1990, com um conjunto de medidas vinculadas, especificamente, à reforma 
da estrutura burocrática do Estado. As reformas econômicas e administrativas, que modernizaram o Estado brasileiro, foram realizadas a partir da eleição do presidente da república Fernando Henrique Cardoso, ${ }^{12}$ que se tornou responsável por esse processo no país, no período de 1995-2002.

$\mathrm{O}$ ministro Bresser-Pereira ${ }^{13}$ e outros intelectuais que participaram do processo de reforma do aparelho do Estado defendiam a introdução, para os diversos setores da administração pública, de um modelo de administração gerencial, regido pelos valores e princípios da empresa privada. Enfatizavam a eficiência, a eficácia, a cobrança, o desempenho, a autonomia financeira, a organização flexível e competitiva, a redução dos níveis hierárquicos e a definição de objetivos quantitativos, a serem atingidos na forma de indicadores de desempenho, como virtudes a serem absorvidas como referência de gestão para os setores públicos estatais e não-estatais.

Bresser-Pereira (1998) recomendou a criação de um modelo de Estado gerencial no Brasil com ênfase à autonomia e à eficiência da administração descentralizada, instituindo como princípio o controle por meio da racionalidade gerencial, do planejamento estratégico, da descentralização administrativa e financeira e da busca de resultados. A reforma gerencial foi um movimento mundial ocorrido na Grã-Bretanha, Austrália, Nova Zelândia, EUA, Suécia, Chile, França, em intensidades diferentes, mas marcado predominantemente por conceitos comuns, como valorização das funções gerenciais na administração pública, controle de resultados, autonomia de gestão, responsabilidade individual na prestação de serviços públicos baseados em metas de desempenho, desenvolvimento de instrumentos que visam a eficiência e a eficácia na gestão, avaliação dos programas e medidas de incentivos aos administradores para melhorar a gestão (BRESSERPEREIRA, 1998).

Nesse sentido, elabora-se uma estrutura para o Estado brasileiro, constituída de um núcleo estratégico, em que seriam definidas as leis e as políticas públicas do Estado, de agências autônomas que devem realizar as atividades exclusivas do Estado, como a segurança pública, o controle, a fiscalização, os subsídios e a seguridade social, cuja forma de administração é gerencial e de serviços não-exclusivos do Estado, como a educação, providos por meio das universidades, escolas técnicas, centros de pesquisa, dentre outros, que devem transformar-se em organizaçôes sociais que recebem recursos do orçamento público, mediante a assinatura de contrato de gestão, mas com autonomia para fecharem acordos e parcerias com instituiçōes privadas, transformando-se em organizaçōes públicas não-estatais (BRASIL, MARE, 1995).

A reforma gerencial do Estado brasileiro pretendia instaurar uma transformação cultural, em relação aos princípios e valores que deveriam reger o processo público administrativo, fortalecendo o controle de desempenho, a avaliação, os resultados, a eficiência, o rendimento etc. Nesse sentido, constituiu-se no Estado brasileiro, sobretudo após a instauração do modelo gerencial de administração pública, um processo de valorização da racionalidade econômica, própria da iniciativa privada, na condução dos negócios públicos.

O processo de constituição do modelo gerencial de administração pública no Estado brasileiro está entrelaçado com as diretrizes para a educação mundial divulgadas nas conferências internacionais de educação, que fortalecem a lógica de modernização da estrutura, organização e gestão das escolas. 
Os organismos multilaterais (BM/FMI/Unesco) contribuem para materializar na sociedade um modo de regulamentação coerente com a atual etapa de acumulação do capitalismo. A educação torna-se um meio para esses organismos disseminarem seu projeto, transformando as relaçóes sociais e alastrando a racionalidade econômica desenvolvida pelos economistas neoliberais de mercado e pelos cientistas sociais na constituição de uma nova hegemonia conservadora, bem como transferindo o modelo gerencial de administração para a organização e a gestão escolar e utilizando a teoria do capital humano para justificar a sua proposta educacional.

Como participante das conferências internacionais e signatário dos documentos elaborados nas conferências dos anos de 1990, o Brasil materializa sua subordinação a esse projeto, que visa a reestruturação da educação nos moldes gerenciais e em conformidade com as necessidades do regime flexível de acumulação, por meio da elaboração de uma legislação educacional que institui esses princípios para o contexto escolar.

O processo é materializado a partir da promulgação da Constituição da República Federativa do Brasil de 1988, no art. 206, inciso VI, que estabelece a gestão democrática do ensino público, na forma de lei (BRASIL, 2000), e por meio dos artigos 14 e 15 da Lei 9.394, de 20 de Dezembro de 1996 - Lei de Diretrizes e Bases da Educação Nacional (BRASIL, 1997), que institui a gestão democrática e a progressiva autonomia das escolas, exigindo dos atores educativos (professores, funcionários, pais, alunos, diretores, coordenadores e outros profissionais da educação) açôes e comportamentos mais ativos na escola. O professor é chamado a participar da gestão no âmbito da escola, especialmente na elaboração da proposta pedagógica ${ }^{14}$ (arts. 12 e 13) e no desenvolvimento de atividades de articulação da escola com as famílias e com a comunidade em geral (BRASIL, 1997).

Esse conjunto de novas políticas e ações envolvendo os diversos agentes escolares pretende impor uma racionalidade econômica ou referenciais econômico-racionais na organização e gestão da escola pública movida pelos princípios da individualidade, da competitividade e da produtividade, que fazem parte do projeto hegemônico liberalconservador de organização da sociedade capitalista e que materializam a retomada do processo de acumulação de capital sob a égide do mercado. O PDE é um dos instrumentos que parece ordenar essas aspirações, e, dentre seus objetivos, busca o direcionamento da ação escolar para obtenção de melhores resultados, acomodando o modelo administrativo gerencial na solução dos problemas da escola.

\section{A RESSIGNIFICAÇÃO DO CONCEITO DE PARTICIPAÇÃO}

Os organismos multilaterais reconhecem que a manutenção de sua hegemonia intelectual e moral depende de um fortalecimento cultural de seus valores. Nesse sentido, elaboraram uma concepção específica a respeito da participação da sociedade civil, conforme apresentado no relatório elaborado por Delors (2001):

Assim, a comunidade pode tomar consciência das condições necessárias ao seu bem-estar e desenvolvimento. A outorga, por parte do Estado, de subsídios às comunidades locais que se esforçam por resolver os seus próprios problemas, aperfeiçoar-se e organizar-se, revelou-se uma 
solução mais eficaz do que as açôes vindas de cima, visando impor o progresso [...] encorajar as iniciativas dos dirigentes locais a aperfeiçoar as suas competências de gestão e conhecimentos técnicos, sobretudo em matéria de controle financeiro [...]. Uma das formas de participação da comunidade é a utilização ou criação de centros comunitários onde pode ser organizado um vasto leque de ações diversificadas: educação dos pais, educação para o desenvolvimento social tratando, por exemplo, de cuidados de saúde primários ou planejamento familiar, educação com vista a melhorar as capacidades econômicas, através de contribuições quer técnicas quer financeiras, etc. [...]. Confiar a membros da comunidade as funçôes de auxiliares ou de paraprofissionais no seio do sistema escolar pode, também, ser considerado uma forma de participação. Assim, a associação de um professor oriundo da própria comunidade com um professor nomeado pelo Estado revelou-se extremamente útil no contexto da recente reforma da educação na Guiné (p. 132-133)

O conceito de participação contido nos documentos apresentados pelos organismos multilaterais busca ressignificar o histórico compromisso e as motivações políticas que envolveram a participação da sociedade civil, reconfigurando a sua essência a uma lógica exclusivamente econômica e moral. Ocorre um processo de transformação da participação da sociedade civil da órbita do Estado de direito para a dimensão do Estado de investimento social regido pela lógica moral da solidariedade social.

As responsabilidades deveriam ser absorvidas pelas pessoas como um estilo de vida ou hábito, encontrando um novo equilíbrio entre o indivíduo e as responsabilidades coletivas. Nesse sentido, construiu-se uma unidade entre indivíduo e solidariedade social, responsabilizando-se moralmente as pessoas a cumprirem suas obrigações (GIDDENS, 1999).

A hegemonia liberal-conservadora ramificada no projeto da Terceira $\mathrm{Via}^{15}$ tem por estratégia de sociabilidade a recriação da sociedade civil como um lócus ativo de colaboração, por meio de ações voluntárias e da responsabilidade social que anulariam as relaçōes e as reivindicaçôes de classe e estimulariam a promoção do bem comum. Para que a "sociedade civil ativa" se desenvolva, é necessário que o Estado recue no provimento dos direitos sociais e incentive o estabelecimento de parcerias com as associações, organizações não governamentais e instituiçôes privadas, a fim de que os "cidadãos" possam exercer a sua parcela de responsabilidade social, bem como é necessário estabelecer uma nova cultura cívica e moral que contenha os princípios da solidariedade, do voluntariado, da preservação da natureza e da responsabilidade social, elementos que, paulatinamente, destituem a sociedade de um comportamento político-reivindicativo dos direitos sociais e condicionam os cidadãos à situação de colaboradores para a diminuição da exclusão social (NEVES, 2005).

Em síntese, transfere-se ao indivíduo a responsabilidade de solucionar os problemas sociais, pelo menos os seus, e isso se configura como participação política. Esse movimento, em geral, revela uma perda da perspectiva universal de classe e, em contrapartida, a intensificação de uma leitura pragmática e imediatista dos problemas sociais.

Em geral, essa concepção de participação da sociedade civil ocorre de forma duplamente subordinada - primeiramente para garantir, precariamente, as mínimas condiçóes de sobrevivência dos grupos excluídos e aplacar os conflitos sociais; em seguida, porque 
se resume à execução de atividades visando o cumprimento de objetivos externamente elaborados, sem qualquer tipo de participação na totalidade do processo.

À medida que a participação da sociedade civil se desloca da órbita do Estado de direito, obedecendo a uma reivindicação histórica e a critérios de natureza pública, coletiva e estatal, migrando para a dimensão individual e da solidariedade social, em que cada grupo se torna responsável pelos resultados alcançados, evidencia-se a necessidade de intensificação das formas de controle e de coerção no interior dos grupos pertencentes à sociedade civil.

Assim, buscou-se construir novos mecanismos de controle, em relação ao micropoder existente nos diversos espaços de organização da sociedade civil, sobretudo na escola. Além disso, os macroresultados devem satisfazer às expectativas gerais de desempenho e de rendimento dos alunos, intensificando o controle, por meio dos procedimentos a serem realizados.

Nesse contexto, em que a participação está condicionada a resultados e a procedimentos, os mecanismos de controle, de acordo com Anderson (2002), dividem-se em três classes:

Os atuais esforços da reforma educativa se baseiam em diferentes combinações de três classes de controle: (a) o controle regulatório, que promove, geralmente desde o nível central, padrões mais altos para professores e alunos; (b) o controle profissional, que se orienta pela melhoria das competências dos educadores e o aumento da tomada de decisões na escola; e (c) o controle democrático, que afirma a possibilidade de as escolas melhorarem mediante o aumento do controle democrático da comunidade educativa escolar. No entanto, o discurso da participação raramente acompanha o primeiro tipo de controle, constituindo um recurso discursivo central nos dois últimos, cada um dos quais outorga poder a diferentes grupos (p. 159-160; tradução nossa).

Esses mecanismos de controle, regulatório, profissional e democrático, tendem a valorizar os procedimentos que se tornam fundamentais para aumentar a produtividade no processo de tomada de decisões e padronizar os comportamentos e atitudes, de tal forma que sirva de referência tanto para a comunidade, como para que os organismos centrais de controle analisem, avaliem e planejem os objetivos a serem alcançados.

Dessa maneira, as formas de controle existentes tendem a condicionar a participação à execução dos procedimentos pré-estabelecidos e à obediência às regras, de modo a naturalizar esses comportamentos e a submeter a participação a esse enquadramento. Em síntese, simultaneamente ao processo de transferência das responsabilidades para a sociedade civil, constituíram-se mecanismos (macro e micro) de controle regulatório. A participação também se transforma em um mecanismo de controle, porque, por meio dela, é possível avaliar, monitorar os comportamentos, as atitudes e o engajamento "ativo" dos grupos pertencentes à sociedade civil, em suma, adequar a participação da sociedade civil à racionalidade econômica, visando o alcance de resultados previamente definidos. 


\section{O MODELO DE PARTICIPAÇÃO INSTITUÍDO PELO PLANO DE DESENVOLVIMENTO DA ESCOLA}

A participação é uma das principais categorias para a apreensão das transformações que ocorreram na escola, após a implementação do PDE, o qual almeja universalizar os princípios baseados na racionalidade econômica e no planejamento estratégico para o conjunto da escola pública.

Em geral, nas escolas públicas existe muito pouca participação do conjunto dos agentes escolares. $\mathrm{Na}$ maioria das vezes, a participação restringe-se a um pequeno grupo responsável pela organização de atividades e eventos. Entretanto, existem alguns elementos que devem ser analisados, para se compreender as razóes para o não-envolvimento do conjunto dos agentes escolares. Dentre elas, a cultura centralizadora, que restringe a participação a um pequeno grupo, responsável pela elaboração e tomada de decisão no espaço escolar, e a concepção de gestão e de organização consubstanciada no plano que fortalece os princípios técnicos e os procedimentos ${ }^{16}$ administrativos gerenciais que estimulam a centralização na tomada de decisōes e impedem a ampliação da participação.

De acordo com Lima (2001),

a defesa da gestão participada e da co-participação, que não da participação na direção e nos processos de decisão, está na ordem do dia e começa a ser transferida para o setor público e para a educação. Este tipo de participação-coesão, funcional e fictício, é claramente entendido como uma técnica de gestão para a promoção da eficácia e da qualidade (p. 132).

Assim, é necessário assinalar que o modelo de co-participação contido no PDE, apesar de teoricamente almejar envolver mais pessoas no processo participativo, restrito à execução das ações, opõe-se qualitativamente ao modelo de participação que historicamente se transformou na reivindicação política de uma grande parcela de educadores progressistas, vinculado à socialização do poder na escola ${ }^{17}$.

O modelo de participação proposto pelo PDE que força os indivíduos a se reunirem, a discutirem, a planejarem os planos de trabalho, a estabelecerem metas, a elaborarem açôes, é visto, por uma grande parcela dos agentes escolares, como positivo para a descentralização do poder, já que estimula a participação do coletivo. Alguns agentes escolares não conseguem perceber que o modelo de participação consubstanciado no PDE centraliza as decisões e fragmenta a execução de atividades. Pelo contrário, consideram que representa um instrumento que estimula maior reflexão e participação, tendo por base um sentido mais universal e coletivo, movimento que não existia anteriormente na escola.

De qualquer forma, os agentes escolares apóiam majoritariamente as iniciativas participativas trazidas pelo plano, como se pode depreender do depoimento de um professor:

o objetivo seria envolver o grupo, pensar coletivamente a escola e começar a agir de uma forma mais coletiva, porque a gente sentia que o trabalho era muito fragmentado [...] mas o principal seria a gente conseguir pensar a escola e juntos tirarmos encaminhamentos para buscar realmente a melhoria do trabalho que a gente tem desenvolvido [...]. O que o PDE poderia trazer de 
contribuição seria uma direção, um caminho que a gente pudesse estar seguindo, para minimizar os problemas que surgem, então, já crônicos, que vêm de algum tempo. Sendo assim, ele dá condições para a gente fazer uma análise mais aprofundada, para a gente poder estar revendo o que a gente já tentou fazer, o que foi possível aproveitar, o que não foi, o que a gente poderia estar fazendo e de que forma se poderia fazer diferente; então seria um instrumento de reflexão e de reorganização das ações no interior das escolas, porque a gente de certa forma fazia as coisas meio por intuição, sem sistematizar, sem organizar (Professor, ex-coordenador do PDE, da escola vermelha).

Entretanto, conseguir a adesão dos agentes escolares visando a participação-execução é um grande problema no desenvolvimento do plano. Aqueles que não participam são rotulados como descompromissados pelos que participam, o que fica evidente quando um professor afirma em dois depoimentos:

...é aquilo que eu te falei, tem um grupo que participa, que interessa, ele é entusiasmado, mas tem uma parte que não tem muito interesse não. É muito trabalho, é muita coisa que tem que fazer, então, tem uma parte que não interessa muito. Mas tem certas pessoas que são entusiasmadas, participam, têm interesse, batalham, vêm em todas as reuniōes, participam, dão opinião, sugestões (Professor da escola vermelha).

...eu acho que, a partir do momento que você está numa escola, você tem que ter interesse, então acontece, como eu falei para você desde o começo, tem pessoas que têm aquele interesse, participam, têm outros que, mesmo não tendo muito interesse participam, mas fazem tudo arrastado, não colabora com uma idéia, não dá uma sugestão, está ali porque é obrigado a estar e pronto (Professor da escola vermelha).

Segundo Lima (2001), é possível definir envolvimento como a atitude ou o empenho dos educadores diante das possibilidades de participação na organização escolar, mais especificamente, a mobilização de esforços na tentativa de defender certos interesses ou soluçôes. Assim, pode-se afirmar que alguns agentes escolares, do ponto de vista do envolvimento, têm uma participação passiva, ou seja, são desinteressados ou alheios às responsabilidades formais de participação existentes na organização.

Lima (2001) esclarece:

O absentismo em geral e a falta de comparência a certas reuniões, a dificuldade de eleição de representantes, a resistência oferecida à aceitação de certos cargos e funções, a falta de informação e o desconhecimento da regulamentação em vigor na organização, especialmente a relativa à participação, são alguns dos elementos mais comuns que a caracterizam (p. 78).

$\mathrm{O}$ pequeno envolvimento dos agentes escolares em relação às atividades propostas pelo PDE pode ser compreendido pela análise da natureza da participação contida no plano. Nesse modelo a participação articula-se com a execução, constituindo um par categorial: participação-execução. Desse modo, a participação associada à execução passa a ser entendida como critério de eficiência na realização das ações e, também, uma espécie 
de parâmetro de avaliação e de demarcação dos limites para a ação dos agentes escolares, o que transforma a participação em uma espécie de técnica de gestão (SILVA, 2004).

Em muitos casos, o grupo que anteriormente centralizava as decisóes na escola continua comandando o processo, o que se coaduna com a estrutura hierárquica do plano; isso revela que uma história de exclusão não se transforma em participação por decreto, mesmo que seja uma participação-execução; por fim, a condição precária de trabalho dificulta a participação dos agentes escolares mesmo daqueles que gostariam de dedicar-se mais.

Esses elementos interferem na participação, apesar de muitos agentes escolares desconsiderarem esses aspectos justificando a artilharia ideológica-coercitiva do PDE contra os descompromissados. A forma de participação é um conceito que pode ser entendido apenas em sua imediaticidade ou percebido em seus vínculos com a estrutura social.

Pode-se resgatar dois aspectos importantes em relação a participação-execução que se instituiu na escola pública. Um deles é a fragmentação dos agentes escolares, que separa os participantes-executores e os descompromissados. Outro aspecto consiste em tornar equivalente participação-execução de ações e participação-socialização do poder.

A participação-execução pode ser entendida como sinônimo de eficiência na realização das ações, mantendo a centralização do poder e a demarcação dos limites para a ação dos agentes escolares na resolução dos problemas da escola. Esses limites são estabelecidos pelas referências econômicas e gerenciais que servem como parâmetro para a tomada de decisóes.

Segundo Lima (2001), a forma de participar necessita de uma regulamentação, ou seja, pressupóe a existência de regras que se constituem como um requisito organizacional ou operacional e servem como uma base de legitimação para que os agentes escolares possam intervir, reivindicar, etc. A referência de participação existente no $\mathrm{PDE}$, no que se refere à regulamentação, segue a lógica formal.

Lima (2001) conceitua participação formal:

É uma forma de participação que, de certo modo, reproduz a participação decretada, no sentido em que está sujeita a um corpo de regras formais-legais relativamente estável, explicitado e organizado, estruturado de forma sistemática e consubstanciado num documento (estatuto, regulamento, etc) com força legal ou hierárquica. A participação formal é aquela que é praticada por referência exclusiva ou predominante as regras formais que, por regulamentarem a participação a um nível normativo, tendem a assumir um caráter muito preciso e a impor orientaçôes e limitaçōes que devem ser observadas em conformidade. (p. 75)

Nesse sentido, a força da regulamentação limita as possibilidades de autonomia dos agentes escolares, restringindo a participação as conformidades formais pré-estabelecidas. Tendo em vista que a forma de participação existente no plano segue essa configuração, no que se refere à regulamentação, resta aos agentes escolares a execução eficiente das ações.

A participação-execução restrita as regras formais, revela uma tentativa de anular outras formas mais universais de participação, vinculadas a preocupações de natureza política e social. Coutinho (1980), atribui um grande valor às organizações e à participação que instituem formas de representação direta, como os partidos de massa, sindicatos, 
associações profissionais, comitê de empresa ou de bairro, pela capacidade dessas organizaçōes se constituírem em sujeitos políticos coletivos e reivindicarem um modelo de democracia de massas que exigem, além da socialização da política, também a socialização do poder.

Nesse sentido, o modelo de participação-execução contido no PDE objetiva sobrepor-se a referência histórica de participação-socialização do poder, que pressupõe um modelo de organização da escola que amplie a autonomia dos sujeitos e construa na escola espaços mais democráticos, para que os sujeitos ultrapassem a regulamentação formal da participação e possam criar experiências mais includentes.

A indiferenciação na maneira de compreender as formas de participação existentes na escola (após a implementação do PDE) pode ser percebida pelo depoimento de um coordenador:

realmente os nomes eram eleitos pelo grupo... quem iria ficar com as açôes do PDE (...). Não é porque você tem uma função de coordenação que você tem que ser responsável por essa área não... é o grupo que, geralmente, sugere o nome ou a pessoa e, ela mesma se autoproclamava: Eu mesma gostaria de estar responsável por essa ação! Então, eu entendo que esse processo foi mais democrático. (Coordenador pedagógico da escola vermelha)

O problema é que, majoritariamente, os agentes escolares não conseguem distinguir essas diferenças. Para a maioria deles, em conseqüência de anos de exclusão de qualquer tipo de participação na escola, o projeto de participação contido no PDE satisfaz suas reivindicações imediatas, mesmo que seja apenas para executar ações, estimulando a participação e incentivando o trabalho coletivo na escola.

No conjunto, percebe-se que alguns agentes escolares participam em muitas circunstâncias para não romperem com os outros colegas da escola, mesmo que, em determinados momentos, sejam coagidos a participar.

Relata um professor, ex-coordenador do PDE:

Em uma reunião, nós aproveitamos um dia de eleição pra diretor pra fazer a primeira minuta do projeto, nesse dia todos os funcionários estavam na escola (...). A gente acreditou que conseguiria pegar pelo menos todo o grupo de sistematização e ai nesse dia a gente continuou com as três, mais a diretora e uma funcionária administrativa, porque o coordenador da noite, eu tive que buscar lá no laboratório de informática, ele ainda se chateou comigo, porque ele achava que não era obrigação dele. Falei assim: Professor nós estamos te esperando. Ah, mas eu estou terminando um serviço. Eu continuei: Professor se você não for, o grupo vai embora e a gente tem umas coisas para fechar, que não dá para fechar sozinho. Ele disse: Não, vocês vai fechando lá, eu não vou não, a hora que eu terminar aqui eu vou. Eu disse: Então nós vamos parar nosso trabalho para esperar você, se você não pode assumir a sua função de auxiliar de ensino, então coloque outra pessoa. Porque na hora eu perdi a paciência, sabe? Ele saiu chateado comigo e foi para lá sentou, mas assim, fez questão só de marcar presença, e aí a gente se sentiu muito sozinha mesmo, nesse dia é que a gente percebeu que, se a gente quisesse concluir, a gente teria que fazer somente nós três, para terminar toda a sistematização do projeto e para responder frente à secretaria (Professor, ex-coordenador do PDE da escola vermelha). 
As ações do PDE, com a racionalidade econômica e a responsabilidade individual que compõe sua estrutura, tornam-se a finalidade suprema da participação na escola.

Um coordenador pedagógico declara:

Quando eu já estava dentro do PDE com o projeto pronto tinha dificuldade um pouco, mas as pessoas participavam e realizavam as ações. Sempre há problemas, um ou outro, sempre tem que estar cobrando, muitas vezes, olha professor, essa questão aqui tal, tal, tal, mas acontecia, não era uma coisa certinha e tudo nos conformes, tinha que estar cobrando, falando, mostrando, conversando, dialogando, mostrando que a gente deveria estar engajado nesse trabalho (...). Eles tiveram que participar e em geral, foi isso aí. (Coordenador pedagógico da escola vermelha)

O PDE com sua racionalidade econômica e procedimentos administrativos gerenciais legitima um maior controle sobre os comportamentos participativos dos agentes escolares, tendo em vista que exige uma série de atitudes e compromissos vinculados às ações.

Nesse sentido, aqueles que não são participantes-executores, são considerados inimigos da escola, por não se adequarem ao modelo proposto pelo plano e por atrasarem o processo que visa angariar maiores recursos e equipamentos para a escola, como assinala um coordenador:

a gente tem que tomar muito cuidado, porque... o limite que separa essa questão de você estar trabalhando de forma a construir um trabalho coletivo usando o PDE como instrumento e aquele onde você pode usar o PDE como instrumento de coerção, de punição, de cobrança, de reforço de seu poder é muito pequeno, se a gente não tomar cuidado, você sai de um e passa para o outro. Tem que tomar muito cuidado. (Professor, ex-coordenador da escola vermelha)

Segundo Anderson (2002), nessas circunstâncias está em jogo a finalidade atribuída à participação. Se a participação objetiva aumentar o rendimento e a produtividade da escola, o enfoque a ser dado deve ser distinto daquele movido por interesses relacionados à socialização do poder. Nesse sentido, quando os participantes esperam resultados relacionados com a eqüidade, mas predominam os interesses relacionados com à produtividade, isso pode gerar confusão, uma vez que os fins não estão bem definidos (ANDERSON, 2002).

Uma grande parcela de agentes escolares somente participam se houver o controle e a cobrança, como declara um coordenador:

...existe participação, mas só que justamente pela questão da cobrança, foi obrigado a aumentar a participação (...) justamente, pela questão da cobrança, mesmo, então aumenta, mas que já existia a participação, era menor é claro, mas existia, então é possível sim, sem o PDE, mas com o PDE é maior. (Coordenador do PDE da escola vermelha)

Percebe-se que na escola, a participação parece constituir um ato obrigatório e somente ocorre, se houver a coerção e o controle realizado pelos próprios membros na escola (ANDERSON, 2002). 
Em geral, a maioria dos agentes escolares acreditam que a forma de participação contida no PDE é propositiva e apesar da baixa participação formal muitos acabam se envolvendo no cumprimento das açōes, não conseguindo resistir ao aumento da coerção e do controle. Esses mecanismos fazem com que, paulatinamente, aumente a adesão e a introjeção dos princípios contidos no plano, apesar dos conflitos existentes.

Alguns agentes escolares têm consciência dos perigos que rondam a concepção de participação-execução presente no PDE, mas insistem em acreditar que, por meio do instrumento metodológico do plano, é possível fortalecer o coletivo e a democracia na escola.

Constitui uma minoria os que têm uma percepção mais crítica em relação ao PDE, demonstrando que nem esse grupo mais crítico consegue vislumbrar outras alternativas para a organização participativa na escola, submetendo-se à lógica economicista instituída pelo plano.

Esse conjunto de elementos revela que, contraditoriamente, os agentes escolares estão internalizando os procedimentos administrativos gerenciais consubstanciados no plano e adequando seus comportamentos a esses referenciais.

\section{CONSIDERAÇÕES FINAIS}

A investigação buscou apreender os processos, o movimento, o modus operandi, a mentalidade, as conseqüências e os desdobramentos do PDE no cotidiano de gestão e de organização do trabalho escolar. Destacaram-se, nesse processo, a compreensão da ressignificação do conceito de participação e as suas articulações com a alteração do regime de acumulação capitalista, que se baseia em uma produção mais flexibilizada e, ao mesmo tempo, em mecanismos mais subjetivos de controle da força de trabalho.

As análises efetuadas evidenciam que o PDE imprime um modelo de gestão centrado em uma lógica economicista e baseado em procedimentos administrativos gerenciais que padroniza e também fragmenta o trabalho docente, ao mesmo tempo em que amplia o controle sobre a ação do coletivo escolar.

Com a implementação do PDE, ainda se observa baixo nível de participação do coletivo escolar, embora não haja discordâncias de caráter político-ideológico em relação aos princípios norteadores do plano. O baixo nível de participação está mais relacionado com a estrutura de implementação do plano e com questóes materiais e objetivas que, efetivamente, dificultam uma participação-execução mais intensa do coletivo escolar. De qualquer modo, na escola pesquisada, percebe-se que os agentes escolares apóiam as iniciativas participativas do plano, uma vez que exige maior "envolvimento de todos".

Em geral, um dos principais desafios consiste em definir qual o sentido e o objetivo principal da participação na escola. Se o objetivo for aumentar o rendimento, o desempenho e a produtividade do aluno, o enfoque a ser dado deve ser distinto daquele exclusivamente movido por interesses relacionados à socialização do poder e à ampliação da democracia política. $\mathrm{Na}$ atualidade, a sociedade brasileira tende a esperar resultados educacionais mais relacionados com interesses individualistas, meritocráticos e competitivos por força do novo processo de acumulação de capital. Entretanto, como um dos principais 
fundamentos para a compreensão do movimento social é a contradição, ainda existe espaço para se restituir os valores políticos e democráticos vinculados a participação.

Para que isso ocorra é necessário um amplo processo de reflexão nacional a respeito do papel da escola e da educação na sociedade brasileira que deve incluir diversos setores efetivamente representativos da sociedade civil, ou seja, instituiçōes que continuam a lutar pela ampliação dos direitos sociais e políticos no interior do Estado democrático de direito, estabelecendo os valores democráticos e a participação-socialização do poder como possibilidades históricas a serem implementadas como políticas de governo. Esse movimento significa, na prática, a participação dessas instituições na elaboração, na implementação e na avaliação dos projetos educacionais, fazendo parte de um consenso nacional que estabeleça a educação com qualidade social como política pública.

\section{Notas}

1. O material apresentado neste artigo refere-se aos resultados de uma pesquisa de mestrado intitulada: As mudanças na gestão e organização da escola: a lógica gerencial e a participação como estratégia da reforma, defendida na Universidade Federal de Goiás. Essa pesquisa foi realizada utilizando dados empíricos coletados nas escolas da rede pública estadual e municipal de Goiânia.

2. Dentre outros produtos do Fundescola, encontram-se: Escola Ativa, Programa de Apoio aos Secretários Municipais de Educação (PRASEM), Plano de Melhoria da Escola (PME), Programa de Adequação do Prédio Escolar (PAPE), Programa de Formação de Professores em Exercício (Proformação), Programa de Gestão da Aprendizagem Escolar (Gestar), Planejamento Estratégico da Secretaria (PES), Programa de Apoio à Leitura e a Escrita (Praler), Programa Melhoria do Rendimento Escolar e o Sistema Integrado de Informações Gerenciais (SiiG), destinado a desenvolver o processo de informatização das secretarias estaduais de educação (BRASIL, MEC, FNDE, 2006).

3. O Fundescola é um programa do Fundo Nacional de Desenvolvimento da Educação, executado em parceria com a Secretaria de Educação Básica do Ministério da Educação (SEB/MEC) e desenvolvido com as secretarias estaduais e municipais de Educação das regiōes Norte, Nordeste e Centro-Oeste. Tem por objetivo promover um conjunto de açôes para a melhoria da qualidade das escolas do ensino fundamental, ampliando a permanência das crianças nas escolas públicas, assim como a escolaridade nas regiôes Norte, Nordeste e CentroOeste. Sua missão é promover, em regime de parceria e responsabilidade social, a eficácia, a eficiência e a eqüidade no ensino fundamental público das regióes Norte, Nordeste e CentroOeste, por meio da oferta de serviços, produtos e assistência técnico-financeira inovadores e de qualidade, que focalizem o ensino-aprendizagem e as práticas gerenciais das escolas e secretarias de educação. O programa é oriundo de um acordo de financiamento entre o Banco Mundial $(\mathrm{BM})$ e o Ministério da Educação (MEC), em que foram firmados três contratos de empréstimos do governo federal com o BM a serem realizados em três etapas, no valor total de um bilhão e trezentos milhōes de dólares (BRASIL, MEC, FNDE, 2006).

4. Na escola, a divisão das tarefas para a elaboração dos planos de trabalho e das ações estratégicas obedece à estrutura fornecida pela brochura intitulada Como elaborar o Plano de Desenvolvimento da Escola: aumentando o desempenho da escola por meio do planejamento eficaz, e divide-se da seguinte forma: Grupo de Sistematização do PDE; Comitê Estratégico; 
Coordenador do PDE; Líderes de Objetivos Estratégicos; Gerentes das Metas de Melhoria; Equipes dos Planos de Ação (AMARAL SOBRINHO; XAVIER, 1999). Esses grupos são responsáveis pela organização das reuniões com o corpo docente em que são elaborados "coletivamente" os planos de trabalho, que contêm as açôes estratégicas e os objetivos pedagógicos que a escola pretende alcançar naquele ano. A análise dos PDEs e a elaboração final dos planos de trabalho anuais seguem uma hierarquia. Inicialmente, a apreciação dos materiais elaborados nas escolas é feita pelas subsecretarias juntamente com o supervisor/orientador municipal. A seguir, os documentos são encaminhados à Gerência de Apoio à Escola (GAE), que faz a análise final e elabora os planos de trabalho anuais, de acordo com a fonte de financiamento. Para a realização desse trabalho, a GAE conta com assessores técnicos e analistas financeiros que trabalham em conjunto com a Superintendência de Planejamento. Após esse processo e elaborados os planos de trabalho anuais, o material deve ser encaminhado à Superintendência de Administração e Finanças e Planejamento e Programação, para as providências de crédito às unidades executoras (UEXs). Com a aprovação do PDE, a escola está liberada para iniciar a sua execução. Caso não seja aprovado, retorna à escola para a reelaboração dos planos de trabalho e açôes estratégicas de acordo com as recomendações dos órgãos responsáveis (GOIÁS, SEE/Coep, 2001 - grifos nossos).

5. Conferência Mundial sobre Educação para Todos (Jomtien, março de 1990), Declaração de Aman (Jordânia, junho de 1996) e Conferência de Dakar (Senegal, abril de 2000).

6. Esses pesquisadores organizaram-se para realizar a pesquisa integrada entre a Universidade Federal de Goiás (UFG) e a Universidade de Brasília (UnB) intitulada Novos modelos de gestão da educação básica: o que mudou na escola?. No total, em Goiânia, foram realizadas 23 entrevistas em cinco escolas públicas municipais e estaduais. Para ampliar os conhecimentos a respeito do conjunto da pesquisa, consultar FONSECA, Marília et alii, 2004.

7. O objetivo da pesquisa foi analisar as transformações na gestão e organização da escola, em especial, as mudanças na forma de participação dos agentes escolares após a implementação do plano. Assim, alguns aspectos articulados com essa discussão, como a melhoria da aprendizagem e a diminuição da evasão escolar como desdobramento da interferência do plano, apesar da relevância, ultrapassam os limites deste trabalho.

8. Em muitos países em desenvolvimento, os organismos multilaterais, como o FMI, condicionam a aplicação das políticas neoliberais à renegociação da dívida externa, forçando esses países a aceitarem o receituário neoliberal de mercado, estabelecido em conformidade com as necessidades de lucro do capital financeiro internacional, em troca de sua inclusão na economia global.

9. Hayek (1990) discordava da solução keynesiana para a crise de oferta de 1929. Para ele, os equívocos econômicos cometidos antes da crise produtiva e que perduraram durante anos, causando um aquecimento produtivo descontrolado, poderiam ter sido resolvidos por outros dispositivos econômicos que reorganizassem o processo sem a interferência sistemática do Estado como agente estimulador do crescimento.

10. A escola de Chicago é herdeira dos princípios monetaristas defendidos por Milton Friedman (Prêmio Nobel de Economia, em 1976), professor na Universidade de Chicago, entre 1946 a 1983. A escola de Chicago sustenta a possibilidade de manter-se a estabilidade de uma economia capitalista apenas por meio de medidas monetárias, baseadas nas forças espontâneas do mercado. Dentre os princípios defendidos por Friedman, e desenvolvidos por seus discípulos, nas diversas áreas do conhecimento, incluindo nas ciências sociais, podem-se destacar a forte desregulamentação estatal, a organização da sociedade baseada no mercado e o individualismo (SANDRONI, 2001).

11. Para Downs (1999), o conceito de racionalidade econômica deve tornar-se, a longo prazo, um padrão de melhor desempenho humano, porque os fatos aleatórios se neutralizam e a eficiência 
triunfa sobre a ineficiência. Esse conceito de racionalidade econômica está sempre ligado a um determinado comportamento humano, que é dirigido, sobretudo, a fins egoístas. Olson (1999) enfatiza a mesma escolha racional como referência para os comportamentos humanos. Seu trabalho analisa o comportamento individual, quando estão em jogo interesses comuns, considerando o grau de envolvimento dos indivíduos isoladamente na busca de seus objetivos pessoais e o grau de envolvimento quando os interesses são comuns.

12. O ex-presidente Fernando Henrique Cardoso compôs um grupo internacional de intelectuais, e entre seus membros ilustres figuravam o primeiro ministro trabalhista inglês Tony Blair e o democrata Bill Clinton, denominados de novos sociais-democratas, que desejavam disseminar os princípios da terceira via como projeto político.

13. Ministro do então Ministério da Administração e Reforma do Estado (Mare), no período de 1994-1998.

14. A denominação utilizada no art. 14 é de projeto pedagógico (BRASIL, 1997).

15. A proposta governamental da Terceira Via vincula-se a uma ramificação teórica que compartilha os mesmos princípios do neoliberalismo de mercado; assim, enfatiza a liberdade individual e o direito de escolha pessoal, acrescentando a essas preocupaçôes questóes como a produtividade econômica, as políticas de participação, a criação de uma responsabilidade social, o desenvolvimento comunitário e, particularmente, a ecologia, bem como a preocupação com a governança na gestão política (GIDDENS, 1999).

16. Trata-se de procedimentos administrativos gerenciais que visam alcançar os objetivos e as metas preestabelecidas por órgãos burocráticos superiores, obedecendo a determinados critérios, como a eficiência, a eficácia, o planejamento estratégico, o cumprimento de metas, o controle do desempenho, a produtividade, a satisfação de resultados etc.

17. A participação-socialização do poder equivale ao conceito gramsciano de participação política, que tem sua origem no valor educativo do partido, que exerce uma influência sobre a formação política de um determinado sujeito, contribuindo para a edificação de uma consciência para si. Para o autor, o partido político deve possibilitar a superação de um estágio de consciência em si, vinculada à fé e ao senso comum, alcançando um outro estágio de desenvolvimento, a consciência para si, vinculada a um projeto histórico-filosófico, no caso específico de Gramsci, à filosofia da práxis. Para Gramsci, a participação política torna-se um aspecto político fundamental para a conquista da hegemonia e está sintetizada na atuação do partido, no interior do parlamento e no conjunto da sociedade civil. Esse processo educa os membros e representantes do partido para utilizar um modelo de participação baseado na organização política, na tomada de decisões e no exercício da socialização do poder (GRAMSCI, 1978).

\section{Referências}

AMARAL SOBRINHO, José. O PDE e a gestão escolar no Brasil. Brasília: MEC/Fundescola, 2001. AMARAL SOBRINHO, José; XAVIER, Antonio Carlos da Ressurreição. Como elaborar o Plano de Desenvolvimento da Escola: aumentando o desempenho da escola por meio do planejamento eficaz. 2. ed. Brasília, 1999.

ANDERSON, Gary L. Hacia una participación auténtica: deconstrucción de los discursos de las reformas participativas en la educación. In: NARODOWSKI, Mariano; NORES, Milagros; ANDRADA, Myrian (Orgs.). Nuevas tendencias en politicas educativas: estado, mercado y escuela. Buenos Aires: Granica, 2002.

BRASIL, Ministério da Administração e Reforma do Estado. Plano Diretor da Reforma do Aparelho do Estado. Brasília: Mare, 1995. 
BRASIL. Lei de Diretrizes e Bases da Educação Nacional. Lei no 9.394/1996, de 20 de dezembro de 1996. Brasília: Subsecretaria de Edições Técnicas, 1997.

BRASIL. Constituição da República Federativa do Brasil. de 05 de outubro de 1988. Brasília: Senado Federal. Subsecretaria de Edições Técnicas, 2000.

BRASIL, MEC, FNDE. O programa. Disponível em: http://www.fnde.gov.br. Acesso em: 01 fev. 2006.

BRESSER-PEREIRA, Luís Carlos. Reforma do Estado para a cidadania: a reforma gerencial brasileira na perspectiva internacional. São Paulo: Editora 34; Brasília: Enap, 1998.

COUTINHO, Carlos Nelson. A democracia como valor universal. São Paulo: Livraria Editora Ciências Humanas, 1980.

DELORS, Jacques (Org.). Educação: um tesouro a descobrir. 6. ed. São Paulo: Cortez; Brasília: MEC: Unesco, 2001.

DOWNS, Anthony. Uma teoria econômica da democracia. Trad.: Sandra Guardini Teixeira Vasconcelos. São Paulo: EdUSP, 1999. (Clássicos 15)

FONSECA, Marília; OLIVEIRA, João Ferreira; TOSCHI, Mirza (Orgs.). Escolas Gerenciadas: planos de desenvolvimento e projetos político-pedagógicos em debate. Goiânia. Editora da UCG, 2004.

FRIEDMAN, Milton. Capitalismo e liberdade. Trad.: Luciana Carli. Editora Artenova, 1977.

GENTILI, Pablo. A falsificação do consenso. 2. ed. Rio de Janeiro: Vozes, 2001.

GIDDENS, Antony. A terceira via. Reflexões sobre o impasse político atual e o futuro da social democracia. Trad.: Maria Luiza X. de A. Borges. 2. ed. Rio de Janeiro: Record, 1999.

GOIÁS. Coordenação Estadual Executiva do Projeto - Fundescola (Coep/GO). Proposta de universalização do PDE. SEE/Coep/GO - Fundescola. Goiânia, 2001.

GRAMSCI, Antonio. Concepção dialética da história. 2. ed. Trad. Carlos Nelson Coutinho. Rio de Janeiro: Civilização Brasileira, 1978.

HAYEK, Friedrich August Von. O caminho da servidão. Trad.: Anna Maria Capovilla, José Ítalo Stelle e Liane de Morais Ribeiro. 5. ed. Rio de Janeiro: Instituto Liberal, 1990.

LIMA, Licínio. A escola como organização educativa: uma abordagem sociológica. São Paulo: Cortez, 2001.

NEVES, Lucia Maria Wanderley (Org.). A nova pedagogia da hegemonia: estratégias do capital para educar o consenso. São Paulo: Xamã, 2005.

OLSON, Mancur. A lógica da ação coletiva: os benefícios públicos e uma teoria dos grupos sociais. Trad. Fabio Fernandez. São Paulo: EdUSP, 1999.

PARO, Victor. Escritos sobre educação. São Paulo: Xamã, 2001.

SANDRONI, Paulo. Novíssimo dicionário de economia. 6. ed. São Paulo: Best Seller, 2001.

SILVA, Luís Gustavo Alexandre. As mudanças na gestão e organização da escola: a lógica gerencial e a participação como estratégia de reforma, 2004. Dissertação (Mestrado) - Universidade Federal de Goiás, Goiânia. 


\section{Changes in the management and organization in the school: the participation as a strategy for reform}

\section{Abstract}

The article intends to show the significant aspects of the implementation in the public school of an example of management of an economic-rational nature, consubstantiated in the Plano de Desenvolvimento da Escola - PDE (School Development Plan - SDP). It also analize the aftermaths or consequences of this movement within the production of school work and in the forms of participation, relating its logic to the wider movement of the transformation of relations of capitalist accumulation. The study showed that the work methodology used by the SPD materializes a model of organizational and school management that limits the school agents to the execution of economic-rational procedures, thus depriving the concept of a more political and universal perspective, aiming at re-dimensioning power in society.

Keywords: School management. Economic rationality. Participation-execution.

\section{Les changements dans l'administration et l'organisation de l'école : la participation comme stratégie pour la réforme}

Résumé

Cet article prétend mettre en évidence les transformations dans la culture scolaire, bien comme les aspects significatifs du processus d'implantation dans l'école publique d'un modèle de gestion de nature économique-rationnelle, consubstantié dans le Plan de Développement de l'École (PDE). Il prétend aussi analyser les suites ou conséquences de ce mouvement à l'intérieur du travail scolaire et dans les formes de participation, relationnant sa logique avec le mouvement plus ample de transformation des relations de l'accumulation capitaliste. Cette étude a mis en évidence que la méthodologie du travail instituée par le PDE matérialise um modèle d'organisation et de gestion de l'école qui limite la participation des agents scolaires à l'exécution de procédures économiques-rationnelles, destituant le concept d'une perspective plus politique et universelle, visant la reconstruction du pouvoir dans la société.

Mots clefs : Gestion scolaire. Rationalité économique. Participation-exécution.

\section{Los cambios en la gestión y organización de la escuela: la participación como estrategia de reforma}

\section{Resumen}

El artículo intenta evidenciar las transformaciones en la cultura escolar, como también los aspectos significativos del proceso de implementación, en la escuela pública, de un modelo de gestión de naturaleza económico-racional, consustanciado en el plan de desarrollo de la escuela (PDE), y analisar los desdoblamientos o consecuencias de ese movimiento en el ámbito de producción del trabajo escolar y en las formas de participación, relacionando su lógica al movimiento ampliado de transformación de las relaciones de acumulación capitalista. El estudio evidenció que la metodología de trabajo instituida por el PDE materializa un modelo gerencial de organización y de gestión de la escuela que limita la participación de los agentes escolares a la ejecución de procedimientos económico-racionales, destituyendo el concepto de una perspectiva más política y universal, que busque el redimensionamiento del poder en la sociedad.

Palabras-clave: Gestión escolar. Racionalidad económica. Participación-ejecución.

Recebida Ia versão em: 24.06.2005

Aceita $2^{\text {a }}$ versão em: 27.03.2006 